\title{
Representações de letramento na BNCC para o Ensino Fundamental nos componentes curriculares Língua Portuguesa e Língua Inglesa
}

\author{
Maísa Helena Brum \\ Instituto Federal do Rio Grande do Sul \\ maisahbrum@gmail.com \\ Cristiane Fuzer \\ Universidade Federal de Santa Maria \\ crisfuzerufsm@gmail.com
}

\section{Resumo}

Este artigo tem como objetivo investigar representações de letramento construídas na Base Nacional Comum Curricular (BNCC) para o Ensino Fundamental nos componentes curriculares Língua Portuguesa e Língua Inglesa da área de Linguagens. Fundamenta a análise linguística deste estudo a perspectiva teórico-metodológica da Linguística Sistêmico-Funcional (HALLIDAY; MATTHIESSEN, 2004; 2014), com foco na metafunção ideacional, realizada pelo sistema de transitividade, a qual dá conta da construção da experiência em termos de configuração de processos, participantes e circunstâncias. As análises revelaram quatro representações para o conceito de letramento na BNCC, a saber: 1) letramento como ação participativa; 2) letramento como gênero discursivo e digital; 3) letramento como diversidade cultura; e 4) letramento como uso de diferentes linguagens. Em conclusão, o texto da BNCC menciona diferentes teorias e metodologias contemporâneas de linguagem, como os multiletramentos. Entretanto, essas referências são essencialmente teóricas, o que leva a um distanciamento entre teoria e prática.

Palavras-chave: Base Nacional Comum Curricular; Representação; Linguística Sistêmico-Funcional; Transitividade.

\section{Abstract}

The present study intends to investigate, by means of the transitivity system, the representations of literacy in the National Common Curricular Base (BNCC, in Portuguese) for Elementary Education in the Portuguese and 
English disciplines. The analysis is based on the theoretical and methodological perspective of Systemic-Functional Linguistics (HALLIDAY; MATTHIESSEN, 2004; 2014), specifically on the ideational metafuncion. The results revealed four representations for the concept of literacy, they are: 1) literacy as participatory action, 2) literacy as discursive and digital genre, 3) literacy as cultural diversity, and 4) literacy as the use of different languages. In conclusion, the document quotes different contemporary theories and language methodologies, as the multiliteracies. However, these references are essentially theoretical, which lead to a gap between theory and practice.

Keywords: National Common Curricular Base; Representation; Systemic Functional Linguistics; Transitivity.

\section{Introdução}

Desde a implementação da Lei de Diretrizes e Bases Nacionais da Educação (LDB) (BRASIL, 1996), o contexto educacional brasileiro vem passando por diversas mudanças no que tange aos documentos oficiais que conduzem a educação brasileira. Uma das mudanças mais recentes foi a implementação da Base Nacional Comum Curricular (doravante BNCC), aprovada pelo Conselho Nacional de Educação em 15 de dezembro de 2017 e homologada em 20 de dezembro do mesmo ano pelo ministro da Educação Mendonça Filho.

A construção e a implementação de uma base curricular que orientasse o ensino público e privado no Brasil já estavam previstas desde 1988 na Constituição Federal de nosso país: "Art. 210. Serão fixados conteúdos mínimos para o ensino fundamental, de maneira a assegurar formação básica comum e respeito aos valores culturais e artísticos, nacionais e regionais" (BRASIL, 1988). E, posteriormente, na Lei de Diretrizes e Base (LDB) de 1996 e no Plano Nacional de Educação de 2014. De acordo com Corrêa e Morgado (2018, p. 2), a "BNCC foi proposta como uma política de Estado que pretendia, apenas, concretizar alguns objetivos que já constavam da legislação do país”.

Um ponto-chave da constituição da BNCC, segundo as divulgações realizadas pelo Ministério da Educação (MEC), foi a construção conjunta por meio de discussões, debates e contribuições de professores e especialistas de diversas áreas. Ainda, segundo o próprio documento da BNCC, ela "foi preparada por especialistas de cada área do conhecimento, com a valiosa participação crítica e propositiva de 
profissionais de ensino e da sociedade civil" (BRASIL, 2017, p. 5). Todavia, temos ciência de que a construção da base pode ter "sido tecida numa atmosfera completamente adversa, fruto de acordos políticos e de tecnologias universalizantes" (CORRÊA; MORGADO, 2018, p. 2), visto que "vale indagar [...] se faz sentido a ideia de ter um currículo deste teor e abrangência; e, ainda, se dele necessitamos e o desejamos" (CORAZZA, 2016, p. 140). Ainda, ao pensarmos se necessitamos e desejamos um currículo "deste teor e abrangência", precisamos também lembrar que é preciso ouvir os professores e reconhecer o poder dos currículos pensados e praticados para as singularidades de cada escola brasileira (SUSSEKIND, 2014).

A BNCC também contou com a participação de qualquer cidadão brasileiro que quisesse postar suas contribuições na própria página da BNCC, nos anos de 2015 e 2016, bem como com uma equipe do governo composta por profissionais de universidades brasileiras. Posteriormente, a primeira versão do documento continuou a ser discutida e desenvolvida a partir de ideias levantadas em cinco audiências públicas promovidas, em 2017, pelo Conselho Nacional de Educação (CNE), em cada uma das regiões do país. Contudo, é importante problematizar se o tempo disponibilizado para as contribuições foi suficiente para realizar um adequado diagnóstico curricular, considerando que

[...] a primeira consulta (restrita) foi iniciada em agosto de 2014; depois, a segunda etapa da consulta (pública) no site (http://basenacionalcomum.mec.gov.br/) começou dia 26 de setembro de 2015 e foi encerrada em 15 de dezembro do mesmo ano, para, então, reabrir até 15 de março de 2016, já contendo um documento que apropriava as 10.379.882 contribuições, intitulado "Encaminhamentos para revisão do documento preliminar da BNCC: proposições a partir dos dados da consulta pública" (CORAZZA, 2016, p. 141).

Levando em consideração que a BNCC busca definir as aprendizagens comuns que devem ser essencialmente desenvolvidas por todos os alunos no decorrer da Educação Básica (BRASIL, p. 7, 2017) e que é um documento novo para as escolas no Brasil, faz-se necessário analisar em que medida as recomendações estabelecidas nesse 
documento vão ao encontro das perspectivas contemporâneas de ensino, especificamente da perspectiva dos letramentos. A pesquisa na área dos letramentos justifica-se pela recorrência, no documento da BNCC, do termo "letramento", o qual aparece 28 vezes, das quais 19 estão na parte destinada à área de linguagens. Em vista disso, este artigo busca investigar como a perspectiva dos letramentos é adotada e compreendida pelo documento da BNCC, especificamente para a área de Linguagens, a qual abarca as disciplinas de Língua Portuguesa, Língua Inglesa, Artes e Educação Física.

O conceito de letramento vem sendo amplamente estudado, principalmente em pesquisas da área da Linguística Aplicada, devido a esse conceito se fazer presente nas abordagens contemporâneas de ensino e aprendizagem e, da mesma maneira, estar latente em muitos de nossos documentos oficiais para a educação, como nas Orientações Curriculares Nacionais (BRASIL, 2006) e nos referenciais teóricos da Secretaria de Educação do Rio Grande do Sul (RIO GRANDE DO SUL, 2009). Rojo e Moura (2012, p. 13) enfatizam a importância de considerar, em um contexto de ensino, a multiplicidade cultural das populações e a multiplicidade semiótica de constituição dos textos por meio dos quais a sociedade se informa e se comunica. Nessa mesma direção, Soares (2002) e Monte Mor (2015) afirmam que um ensino plural e situado oferece e promove uma aprendizagem mais contextualizada e crítica aos educandos.

Nessa perspectiva dos letramentos no campo da educação, algumas pesquisas já buscaram compreender as representações, por meio de princípios da Linguística Sistêmico-Funcional, de concepções subjacentes aos discursos de professores, de alunos e também a discursos em documentos institucionais no âmbito educacional. Batista (2012), por exemplo, analisou a representação da prática pedagógica no ensino de inglês na escola pública; Alves (2016) identificou as representações de educação em publicações de jornais da cidade de São Paulo; e Cargnin e Fuzer (2017) buscaram identificar as representações de professor em discursos de paraninfos na área de Letras.

A fim de dar continuidade aos estudos sobre representações no contexto escolar, na perspectiva da Linguística Sistêmico-Funcional, este artigo tem como objetivo principal investigar representações de letramento manifestadas nas seções relativas aos componentes curriculares Língua Portuguesa e Língua Inglesa na BNCC para o 
Ensino Fundamental. Mais especificamente, identifica e analisa funções léxico-gramaticais dos expoentes linguísticos que remetem ao conceito de letramento nas seções relativas aos componentes curriculares Língua Portuguesa e Língua Inglesa na BNCC, com base na descrição do sistema de transitividade, a fim de evidenciar as representações de letramento.

A seguir, discorremos sobre os pressupostos teóricometodológicos que embasam esta investigação: o conceito de letramento e os princípios da Linguística Sistêmico-Funcional para análise de representações em textos.

\section{$2 \mathrm{O}$ conceito de letramento}

Em sua etimologia, a palavra letramento surgiu do termo literacy, em inglês. Essa palavra, segundo Soares (2010, p. 17), é formada com base no termo em latim littera, que significa letra, com o acréscimo do sufixo “-cy”, que indica qualidade ou estado de ser letrado. Nesse sentido, literacy significa a condição ou o estado de ser letrado, isto é, de ser capaz de ler e escrever. Todavia, essa definição para letramento vem sendo (re)elaborada e (re)construída, dadas as transformações culturais, sociais e tecnológicas do mundo que afetam, sobretudo, o campo educacional. Dessa forma, o conceito de letramento expandiu-se para além da capacidade de saber ler e escrever.

Nessa perspectiva de transformação, Soares e Batista (2005, p. 50) definem letramento como um "conjunto de conhecimentos, atitudes e capacidades envolvidos no uso da língua em práticas sociais e necessários para uma participação ativa e competente na cultura escrita". Na definição desses autores, o conceito de letramento se expande de uma visão essencialmente alfabetizadora para uma visão de letramento como prática social, isto é, saber ler e escrever para atuar no mundo.

Freire (2011), em seus escritos sobre alfabetização, mesmo sem usar o termo letramento, já salientava que as ações de ler e escrever são processos que vão além da decodificação de letras e/ou sons e da apropriação do alfabeto, pois envolvem também a percepção crítica, a interpretação e a reescrita de textos. Em outras palavras, ser letrado é apropriar-se das práticas sociais de leitura e escrita (ROJO, 2004) com 
vistas a transformar o mundo por meio de uma prática sociocultural crítica e consciente (FREIRE, 2011).

A maneira como Freire concebia o processo de alfabetização, em sua pedagogia, está intimamente relacionada ao que definimos, no status quo da área da Linguística Aplicada, como letramentos e multiletramentos, termo contemporâneo utilizado na área. Monte Mor (2015, p. 189) menciona que os preceitos dos letramentos repercutiram em nosso país em vista da afinidade com os ideais freireanos disseminados há décadas atrás. Assim, nas considerações de Street (1984), letramento é definido como uma prática social que não pode ser entendida separada de seus princípios epistemológicos socialmente construídos. Em outras palavras, o letramento é sempre ideológico, pois está enraizado em maneiras particulares de ver o mundo. O letramento, segundo Barton e Hamilton (2012, p. 3), também pode ser entendido como uma atividade "entre pensamento e texto" de tal maneira que as habilidades aprendidas são colocadas em prática por meio de interações entre pessoas.

A linguagem, nesse panorama, é vista como um recurso dinâmico representacional, o qual é constantemente feito e refeito por seus usuários enquanto eles trabalham para atingir seus diversos propósitos culturais (THE NEW LONDON GROUP, 1996/2000, p. 5). Portanto, incorporado a essa concepção de linguagem, o letramento, na área da Linguística Aplicada, pode ser compreendido como uma prática sociocultural de engajamento do indivíduo em atividades sociais de prática de leitura, escrita e tantos outros modos de significação da linguagem.

\section{0 sistema de transitividade na linguística sistêmico-funcional}

Para revelar representações em discursos, a Linguística Sistêmico-Funcional oferece um conjunto de conceitos e categorias que propiciam a descrição e a análise de sistemas léxico-gramaticais e semânticos associados ao contexto em que um texto é produzido e veiculado socialmente. A linguagem, nessa teoria, é definida como um sistema sociossemiótico e, segundo Halliday e Matthiessen (2014, p. 3), "é, em primeiro lugar, um recurso para produzir sentidos; então o texto 
é um processo de produzir sentidos dentro de um contexto". ${ }^{1}$ Instanciada em textos, a linguagem desempenha três metafunções: representar o mundo, ser um instrumento de interação e organizar a informação (HALLIDAY; MATTHIESSEN, 2014). Essas três metafunções são denominadas, respectivamente, de ideacional, interpessoal e textual (HALLIDAY; MATTHIESSEN, 2004).

Neste trabalho, focalizamos a linguagem usada para construir representações num contexto social específico: o contexto educacional regido por normas políticas. Assim, a prática social que permeia esse contexto está relacionada aos atos normativos e governamentais assumidos pelo governo federal a fim de embasar o ensino básico brasileiro. A Linguística Sistêmico-Funcional (doravante LSF), como uma abordagem teórico-metodológica para análise dos usos da linguagem, vai ao encontro dos objetivos propostos neste estudo, visto que se pretende investigar, por meio da análise da linguagem escrita, os conceitos subjacentes ao letramento no documento da BNCC. Isso é possível porque a LSF "permite-nos investigar como a experiência é construída em termos semânticos e como essa experiência se manifesta nos diferentes estratos da língua" (FUZER; CABRAL, 2014, p. 25).

Para a teoria sistêmico-funcional, a linguagem está organizada de maneira funcional em uma rede de sistemas de significação. Essa organização se dá "em torno de redes relativamente independentes de escolhas" (GOUVEIA, 2009, p. 15) realizadas pelo falante, que variam de acordo com as situações de uso da linguagem. A metafunção ideacional, nesse sentido, representa as experiências do falante ou escritor em relação a um contexto específico.

Para esta investigação, a análise focaliza, especificamente, a metafunção ideacional experiencial, que se realiza léxicogramaticalmente pelo sistema da transitividade, o qual possibilita explicar a construção das experiências nos textos. A função experiencial, responsável pela construção de um modelo de representação de mundo (FUZER; CABRAL; OLIONI, 2011, p. 189), tem sua unidade de análise na oração e seus componentes: processos, participantes e circunstâncias (HALLIDAY; MATTHIESSEN, 2004). Nesse sentido, Halliday e Matthiessen (2004, p. 169) argumentam que,

\footnotetext{
${ }^{1}$ Nossa tradução. No original: Language is, in the first instance, a resource for making meaning; so text is a process of making meaning in context.
} 
ao construirmos o mundo das experiências, formamos uma "figura", a qual é constituída pelos participantes e pelos processos, ou seja, por quem faz o quê, e eventualmente pelas circunstâncias de tempo, modo, causa, localização e outras associadas aos processos.

De acordo com Halliday e Matthiessen (2014, p. 213), "cada tipo de figura realizado pela oração expressa um processo que se desdobra através do tempo, com participantes diretamente envolvidos nesse processo de alguma maneira. As circunstâncias, por sua vez, não estão diretamente envolvidas no processo, mas estão correlacionadas a ele". 2 Tipicamente, os processos realizam-se por meio de grupos verbais, os participantes por meio de grupos nominais e as circunstâncias por grupos adverbiais ou sintagmas preposicionais.

O processo é o núcleo experiencial da oração, que pode ser do tipo básico (processos materiais, mentais e relacionais) e do tipo que traz traços de dois os mais processos básicos (processos comportamentais, verbais e existenciais). Os processos materiais são processos de fazer e acontecer relacionados a ações do mundo físico, isto é, de experiências concretas de criação ou transformação (HALLIDAY; MATTHIESSEN, 2004), como, por exemplo, os processos "fazer" e "criar". Nesse tipo de processo estão envolvidos dois participantes principais: o Ator, que é o agente do processo, e a Meta, que é a entidade modificada de alguma forma pelo processo.

Os processos mentais, como "pensar" e "duvidar", são processos de sentir e são relativos às ações que não acontecem no mundo físico, mas sim no mundo da consciência do ser humano (HALLIDAY; MATTHIESSEN, 2004). Os participantes principais desse tipo de processo são o Experienciador e o Fenômeno. O primeiro é aquele que percebe, pensa, deseja ou sente, e o segundo é aquilo que é percebido, pensado, desejado ou sentido.

Por sua vez, os processos relacionais configuram relações que se estabelecem entre duas entidades, isto é, eles possuem uma função classificatória que relaciona duas entidades num discurso, o identificado

\footnotetext{
${ }^{2}$ Nossa tradução. No original: All figures consist of a process unfolding through time and of participants being directly involved in this process in some way; and in addition there may be circumstances of time, space, cause, manner or one of a few other types. These circumstances are not directly involved in the process; rather they are attendant on it.
} 
e o identificador, e/ou o portador e o seu atributo (HALLIDAY; MATTHIESSEN, 2014). Exemplos desse tipo de processo são os verbos "ser", "estar" e "ter".

Em relação aos processos fronteiriços, Halliday e Matthiessen (2004) classificam-nos em três: comportamentais, verbais e existenciais. Os processos comportamentais são tipicamente humanos, que englobam comportamentos físicos e psicológicos, como respirar, olhar, sorrir, entre outros. Esses processos, segundo os autores, estão entre os materiais e mentais, e seus participantes são o Comportante, entidade que realiza a ação, e o Comportamento, o qual define o escopo do processo.

Os processos verbais, por sua vez, são processos de “dizer" e estão na fronteira entre os processos mentais e os relacionais, como os verbos "falar" e "responder". Seus participantes são quatro: o Dizente, aquele que diz; o Receptor, aquele para quem a mensagem se dirige; o Alvo, a entidade que é atingida pelo processo; e a Verbiagem, a mensagem propriamente dita.

Por fim, os processos existenciais são aqueles que se encontram entre os processos relacionais e os materiais e expressam proposições existenciais. Exemplos são "existir" e "haver". Esse tipo de processo representa algo que existe ou acontece e tem como único participante o Existente (HALLIDAY; MATHIESSEN, 2014).

Considerada componente opcional e eventual da oração, a Circunstância é definida como "um processo que se tornou parasita em outro processo, ao invés de significar por ela mesma, ela serve como uma expansão de outro processo ou participante" 3 (HALLIDAY; MATTHIESSEN, 2014, p. 312). Os autores a classificam em nove diferentes tipos: extensão, localização, modo, causa, contingência, acompanhamento, papel, assunto e ângulo.

Neste estudo, utilizamos também o conceito de metáfora gramatical (MG) como "um processo pelo qual significados são

\footnotetext{
${ }^{3}$ Nossa tradução. No original: We are able to do this because a circumstantial element is itself, from this point of view, a process that has become parasitic on another process. Instead of standing on its own, it serves as an expansion of something else.
} 
codificados multiplamente no nível da gramática" 4 (MARTIN, 1996, p. 235, segundo em HALLIDAY, 1985). Especialmente no texto escrito, muitas orações com metáforas gramaticais possuem tanto uma leitura literal quanto outras interpretações e, por isso, faz-se necessário o "desempacotamento" dessas informações para que se possa compreender completamente o sentido da oração analisada (MARTIN, 1996). Nas frases (a) e (b) a seguir, retiradas de um exemplo fornecido por Halliday e Matthiessen (2014, p. 727), podemos perceber como um processo pode ser modificado para se tornar um grupo nominal "empacotado".

a) "Porque a tecnologia está melhorando, as pessoas são capazes de compor programas de negócio mais rápidos".

b) "Avanços na tecnologia estão acelerando a composição de programas de negócio". 5

Os processos "está melhorando" e "compor", em (a), são usados como grupos nominais, em (b): "avanços" e "composição", respectivamente. Nesse sentido, os significados experienciais dos processos em (a) foram "empacotados" em grupos nominais em (b).

Em (c) (extraído do corpus desta pesquisa), o grupo nominal "ampliação" é uma metáfora gramatical, visto que surge a partir do processo "ampliar".

c) Ao componente Língua Portuguesa cabe, então, proporcionar aos estudantes experiências que contribuam para a ampliação dos letramentos.

Em síntese, a "metáfora gramatical é considerada uma maneira metafórica de construir sentido, no qual um processo é realizado por um

\footnotetext{
${ }^{4}$ Nossa tradução. No original: grammatical metaphor is the process whereby meanings are multiply-coded at the level of grammar.

${ }^{5}$ Nossa tradução. No original: Because technology is getting better, people are able to write business programs faster. Advances in technology are speeding up the writing of business programs.
} 
substantivo e uma qualidade é realizada por um adjetivo, na léxicogramática"6 (DEVRIM, 2015, p. 2).

Partindo da noção de linguagem como sistema sociossemiótico que desempenha funções, focalizamos a metafunção ideacional experiencial a fim de evidenciar as representações para o conceito de letramento na BNCC. Na sequência, descrevemos o universo de análise - o texto da BNCC para a área do português e inglês -, bem como os procedimentos adotados no desenvolvimento da análise sistêmicofuncional.

\section{Metodologia}

\subsection{Universo de análise: a BNCC}

A BNCC é um documento de caráter normativo que define "o conjunto orgânico e progressivo de aprendizagens essenciais que todos os alunos devem desenvolver ao longo das etapas e modalidades da Educação Básica" (BRASIL, 2017, p. 7). Ela foi construída por meio de um processo que durou quase quatro anos. No ano de 2014, o Plano Nacional de Educação definiu a BNCC como estratégia para alcançar quatro metas fixadas pelo plano. A primeira delas seria universalizar, até o ano de 2016,

a educação infantil na pré-escola para as crianças de 4 (quatro) a 5 (cinco) anos de idade e ampliar a oferta de educação infantil em creches de forma a atender, no mínimo, $50 \%$ (cinquenta por cento) das crianças de até 3 (três) anos até o final da vigência deste PNE (BRASIL, 2014).

A segunda meta referia-se à universalização do ensino fundamental de nove anos "para toda a população de 6 a 14 anos e garantir que pelo menos $95 \%$ dos alunos concluam essa etapa na idade recomendada, até o último ano de vigência deste PNE" (BRASIL,

\footnotetext{
${ }^{6}$ Nossa tradução. No original: experiential metaphor is considered the metaphorical ways of meaning making where process (with a small $p$ ) is realized by a noun, and quality is realized by an adjective in lexicogrammar.
} 
2014). Por sua vez, a terceira meta fazia menção à universalização do ensino para adolescentes frequentadores do ensino médio brasileiro. Por fim, a quarta meta relaciona-se com o fomento da qualidade da educação básica e a melhoria nas médias nacionais para o Índice de Desenvolvimento da Educação Básica (Ideb).

Segundo o site institucional da BNCC, para dar conta dessa universalização, o documento preliminar da base foi escrito por pesquisadores da educação, de julho a setembro de 2015; após esse período, o documento tornou-se público para que a sociedade pudesse contribuir. A consulta pública ficou disponível de outubro de 2015 a março de 2016 por meio do site http://movimentopelabase.org.br. Após a compilação dessas contribuições, um novo documento foi disponibilizado em maio de 2016; de junho a agosto desse mesmo ano, o documento foi debatido em seminários estaduais promovidos pelo Conselho Nacional de Secretários da Educação (Consed).

Ainda, de acordo com o site do MEC, em setembro de 2016, o Consed entregou ao MEC as contribuições oriundas desses seminários, e em abril de 2017 o MEC entregou ao CNE a terceira versão da BNCC. De junho a setembro desse mesmo ano, o CNE realizou consultas públicas para ouvir a sociedade sobre a terceira versão, e em 15 de dezembro de 2017 o CNE aprovou a BNCC por vinte votos a três, passando a valer a BNCC em todo o país a partir de 20 de dezembro de 2017, data em que foi homologada. Entretanto, cabe salientar que não houve clareza em relação a como as consultas foram, de fato, mencionadas e utilizadas nas versões da BNCC.

A BNCC traz normativas construídas com o propósito de nortear "os currículos dos sistemas e redes de ensino do país, como também as propostas pedagógicas de todas as escolas públicas e privadas de Educação Infantil, Ensino Fundamental e Ensino Médio, em todo o Brasil" (BRASIL, 2017). Essa versão da BNCC, homologada em 20 de dezembro de 2017, foi desenvolvida focalizando nos conteúdos e competências para o Ensino Infantil e o Ensino Fundamental. Como proposto em seu documento final, ela procura estabelecer conhecimentos, competências e habilidades que se espera que todos os estudantes desenvolvam ao longo da escolaridade básica. 


\subsection{Procedimentos de seleção e análise dos dados}

O universo de análise desta pesquisa compreende o texto da BNCC, disponibilizado em seu site (http://basenacionalcomum.mec.gov.br/a-base/). No que tange ao corpus da pesquisa, realizamos um recorte do documento, focalizando as seções relativas aos componentes curriculares Língua Portuguesa e Língua Inglesa, situados na seção "Área de linguagens”.

Dessas duas seções selecionamos as orações que traziam a palavra-chave "letramento" e seus referentes com campos semânticos afins, como "multiletramento", "prática social", "linguagem", "multissemiótico" e "multicultural".

Em cada uma das orações selecionadas realizamos a análise das funções léxico-gramaticais no sistema de transitividade desempenhadas pelas palavras-chave e seus referentes. Na sequência, mapeamos, sistematizamos e interpretamos as representações evidenciadas nas orações analisadas.

Em algumas das orações selecionadas foi necessário analisar as metáforas gramaticais e, consequentemente, realizar seu "desempacotamento" para elucidar a representação de letramento contida na oração. A recorrência de metáforas gramaticais deu-se pelo fato de o texto ser um documento regulatório, o qual pode vir a ocultar os atores sociais no texto, visto que as "representações incluem ou excluem atores sociais para servir os seus interesses e propósitos em relação aos leitores a quem se dirigem" (VAN LEEUWEN, 1997, p. 180).

\section{Resultados}

Nesta seção apresentamos as quatro representações para o conceito de letramento que emergiram do corpus a partir da análise da transitividade, quais sejam: Letramento como ação participativa; Letramento como gênero discursivo e digital; Letramento como diversidade cultural; e Letramento como uso de diferentes linguagens. 


\subsection{Letramento como ação participativa}

No início de cada seção das disciplinas que compõem a BNCC, há uma descrição sobre o objetivo que compete a cada disciplina em relação aos conhecimentos trabalhados em sala de aula. O Exemplo ${ }^{7} 1$ traz o objetivo do componente Língua Portuguesa:

\section{Exemplo 1}

Ao componente Língua Portuguesa cabe, então, proporcionar aos estudantes experiências que contribuam para a ampliação dos letramentos, de forma a possibilitar a participação significativa e crítica nas diversas práticas sociais permeadas/constituídas pela oralidade, pela escrita e por outras linguagens.

No Exemplo 1 há, pelo menos, duas metáforas gramaticais (doravante MG) que circundam as palavras-chave. A primeira MG pode ser identificada na nominalização do processo "ampliar", referindo-se à “ampliação dos letramentos". Nessa oração, letramento é compreendido como um Fenômeno do processo mental "ampliar", empacotado na MG; e as experiências vivenciadas pelos estudantes tornam-se o Experienciador desse processo. Ao identificar o letramento como um Fenômeno gerado por meio das experiências dos alunos, é possível representá-lo como uma experiência contextual. Em outras palavras, nesse excerto, letramento é entendido como algo percebido e vivenciado pelo aluno em suas experiências diárias. Ao olharmos para os processos materiais abstratos "proporcionar" e "possibilitar", podemos compreender que o Ator desse processo, mesmo implícito nas orações, seria o próprio professor, aquele que é responsável por proporcionar o conhecimento ao aluno.

Ainda no Exemplo 1, verifica-se a presença de outra MG sinalizada pela nominalização do processo "participar". Nessa oração, compreende-se que o Ator do processo material "participar", nominalizado no exemplo por "participação", seria os próprios estudantes. Essa participação vem acompanhada de duas Circunstâncias,

\footnotetext{
${ }^{7}$ Em todos os exemplos estão sublinhadas as palavras-chave que auxiliaram na seleção dos dados.
} 
uma de Modo, "significativa e criticamente", e uma de Lugar, "nas diversas práticas sociais". A segunda explica em que situações o aluno pode ampliar seu letramento, e a primeira explica de que maneira o aluno poderia participar nessas práticas letradas.

O Exemplo 1, ao mencionar uma participação crítica em diferentes práticas sociais, vai ao encontro de uma representação de letramento como forma de posicionar-se ativamente e agir sobre/no mundo, como proposto nas Orientações Curriculares para o Ensino Médio (OCN) (BRASIL, 2006, p. 112).

No Exemplo 2, na seção do componente Língua Inglesa, a BNCC argumenta sobre as implicações de ensinar inglês sob uma perspectiva de educação linguística, consciente e crítica.

\section{Exemplo 2 \\ Ensinar inglês com essa finalidade tem, para o currículo, três implicações importantes [...] A segunda implicação diz respeito à ampliação da visão de letramento, ou melhor, dos multiletramentos, concebida também nas práticas sociais do mundo digital - no qual saber a língua inglesa potencializa as possibilidades de participação e circulação - que aproximam e entrelaçam diferentes semioses e linguagens (verbal, visual, corporal, audiovisual), em um contínuo processo de significação contextualizado, dialógico e ideológico.}

Novamente, no Exemplo 2, verifica-se a ocorrência de uma MG a partir da nominalização do processo em "ampliação". Há também um apagamento do possível Experienciador do Fenômeno "visão"; porém, pressupõe-se que sejam os professores do componente curricular Língua Inglesa, visto que o parágrafo que introduz as três implicações menciona a finalidade de "ensinar" inglês. O termo "letramento", nesse exemplo, exerce também a função de Fenômeno, o que indica o letramento como uma cultura letrada da qual o professor faz parte e conhece, isto é, algo que já está dado ao professor.

No Exemplo 2, o trecho "saber a língua inglesa potencializa as possibilidades de participação e circulação" no mundo digital, as duas MG, nas nominalizações "participação" e "circulação", são oriundas de processos materiais, o que implica a presença de um Ator. Nesse caso, o Ator é "saber a língua inglesa". O Experienciador de "saber", por sua vez, são, possivelmente, os aprendizes. Nesse sentido, o Exemplo 2 
também expressa a representação de letramento como uma ação participativa concreta.

\subsection{Letramento como gênero discursivo e digital}

Na seção do componente Língua Portuguesa, a BNCC discute a necessidade de se trabalhar com gêneros discursivos de cunho digital em sala de aula, porém sem deixar de considerar os gêneros já consagrados pela escola. O Exemplo 3 retrata os gêneros discursivos que devem ser trabalhados em sala de aula, tanto os impressos como os digitais.

\section{Exemplo 3}

Não se trata de deixar de privilegiar o escrito/impresso nem de deixar de considerar gêneros e práticas consagrados pela escola, tais como notícia, reportagem, entrevista, artigo de opinião, charge, tirinha, crônica, conto, verbete de enciclopédia, artigo de divulgação científica, etc., próprios do letramento da letra e do impresso, mas de contemplar também os novos letramentos, essencialmente digitais.

No Exemplo 3, para o componente de Língua Portuguesa, é necessário "contemplar também os novos letramentos". O processo mental "contemplar" vem acompanhado do Fenômeno "novos letramentos" e implica um participante que é almejado na prática de Língua Portuguesa, visto que se deve mesclar o trabalho com gêneros digitais e gêneros canônicos na disciplina. Embora o participante Experienciador esteja omitido na oração, pressupõe-se que ele seja o professor da disciplina, o qual estaria apto a abordar, em suas aulas, o uso de diferentes gêneros, "essencialmente digitais". Nesse exemplo, o letramento implica o uso de gêneros discursivos pelo uso do letramento como Fenômeno de experiências mentais associado a diferentes gêneros.

Para o componente Língua Inglesa, a BNCC também sinaliza, em diversos momentos, a relevância de um ensino com base nas novas tecnologias. O Exemplo 4 aborda uma das competências específicas elencadas para o alunado no componente Língua Inglesa na BNCC. 


\section{Exemplo 4}

Comunicar-se na língua inglesa, por meio do uso variado de linguagens em mídias impressas ou digitais, reconhecendo-a como ferramenta de acesso ao conhecimento, de ampliação das perspectivas e de possibilidades para a compreensão dos valores e interesses de outras culturas e para o exercício do protagonismo social.

No Exemplo 4, os estudantes, na disciplina de Inglês, devem ser capazes de se comunicar na língua inglesa utilizando diferentes modos de significar na língua. O processo verbal "comunicar-se" e o seu Alvo a "língua inglesa" são acompanhados da Circunstância "por meio do uso variado de linguagens em mídias impressas ou digitais", a qual expande de que maneira o estudante pode aprender a se comunicar em inglês. Ao focalizarmos somente a Circunstância, percebemos que a representação de letramento implica o uso de gêneros de diferentes mídias, corroborando, assim, para o entendimento de que o letramento é promovido e mediado por textos (OLIVEIRA, 2010 segundo BAZERMAN, 2005).

\subsection{Letramento como diversidade cultural}

O componente Língua Portuguesa, em sua seção, menciona a inclusão da cultura digital como um de seus objetivos. O Exemplo 5 expande esse objetivo ao incluir a diversidade cultural também como foco do componente.

\section{Exemplo 5}

Da mesma maneira, imbricada à questão dos multiletramentos, essa proposta considera, como uma de suas premissas, a diversidade cultural.

Nesse excerto, o processo mental cognitivo "considera" tem como Experienciador "a proposta", que se refere ao texto da BNCC; e como Fenômeno "a diversidade cultural". Para a BNCC, a diversidade cultural está intimamente conectada “(imbricada) à questão dos multiletramentos", a qual é uma oração encaixada que funciona como Atributo em relação a "essa proposta". O processo relacional "imbricar", por sua vez, tem como participante Identificado "essa proposta" e como 
Identificador "a questão dos multiletramentos", o que implica pensar que a perspectiva dos Multiletramentos serve para definir a identidade da proposta da BNCC.

Da mesma forma, o componente Língua Inglesa, no Exemplo 6, retrata o letramento como uma maneira de reconhecer as pluralidades das práticas sociais. O excerto está discutindo a abordagem da língua inglesa como língua franca e a relevância do uso da língua em contextos locais.

\section{Exemplo 6}

Esse entendimento favorece uma educação linguística voltada para a interculturalidade, isto é, para o reconhecimento das (e o respeito às) diferenças, e para a compreensão de como elas são produzidas nas diversas práticas sociais de linguagem, o que favorece a reflexão crítica sobre diferentes modos de ver e de analisar o mundo, o(s) outro(s) e a si mesmo.

Nesse exemplo são usadas várias MGs por meio das nominalizações "entendimento", "reconhecimento", "compreensão" e "reflexão". Em relação à nominalização "reconhecimento", o processo mental "reconhecer" tem como Fenômeno "das diferenças" e, novamente, o Experienciador encontra-se suprimido na oração, mas infere-se que seria o estudante o indivíduo que precisa reconhecer as diferenças culturais a fim de promover a diversidade. Outra MG, nesse excerto, está presente na nominalização do processo também mental "compreender". Os dois processos mentais salientados no Exemplo 6 apresentam Experienciadores omissos; isso se deve ao caráter do texto da BNCC: um texto normativo.

\subsection{Letramento como uso de diferentes linguagens}

No texto introdutório à seção do componente Língua Portuguesa, o texto da BNCC menciona a relação existente entre prática social e diferentes linguagens, como se verifica no Exemplo 7.

\section{Exemplo 7}

As atividades humanas realizam-se nas práticas sociais, mediadas por diferentes linguagens: verbal (oral ou visual- 
motora, como Libras, e escrita), corporal, visual, sonora e, contemporaneamente, digital.

O Exemplo 7 corrobora a relação das práticas sociais com a perspectiva dos letramentos ao expandi-las a partir da Circunstância de Modo "mediadas por diferentes linguagens [...]", visto que essa Circunstância explica como as práticas sociais constituem as atividades humanas por meio da mediação de diferentes linguagens. Isso implica uma representação de letramento como a mobilização de diferentes modos de significar em uma língua, seja ele oral, corporal, visual, entre outros modos. Essa representação vai ao encontro da concepção de multiletramento proposta por Cope e Kalantzis (2009, p. 167), a qual pressupõe "novas e transformadas formas de uso da linguagem, novas maneiras de participar como cidadão em espaços públicos, e também, talvez, em novas formas de identidade e personalidade". ${ }^{8}$

\section{Considerações finais}

Com base no aparato teórico-metodológico sobre o sistema de transitividade da Gramática Sistêmico-Funcional (HALLIDAY; MATTHIESSEN, 2004; 2014) para a análise de representações, foram encontradas, nas seções dos componentes curriculares Língua Portuguesa e Língua Inglesa da BNCC, quatro representações para o conceito de letramento subjacente a esse documento. Na representação de letramento como ação participativa, observamos que a BNCC busca possibilitar uma aprendizagem participativa, nas áreas de Língua Portuguesa e Língua Inglesa, que, em última instância, leve o estudante a se colocar como agente da produção do conhecimento. A representação de letramento como gênero discursivo e digital, por sua vez, salienta o interesse em promover a leitura e a produção de diferentes gêneros e tipos de texto. Por sua vez, o letramento como diversidade cultural vai ao encontro de uma prática consciente que leve os alunos a

\footnotetext{
${ }^{8}$ Nossa tradução. No original: ways of working in new or transformed forms of employment, new ways of participating as a citizen in public spaces, and even perhaps new forms of identity and personality.
} 
compreenderem melhor a cultura de contextos diferentes, bem como de seu próprio.

Por fim, a representação de letramento como uso de diferentes linguagens conecta-se aos diferentes modos de significar na língua, visto que esses novos modos de significar implicam, na prática pedagógica, a percepção e a negociação de uma multiplicidade de discursos (THE NEW LONDON GROUP, 1996/2000). A recorrência de processos mentais nos excertos selecionados e também de metáforas gramaticais por nominalização pode explicar-se pela característica normativa do texto. A BNCC busca fornecer explicações teóricas e instrucionais sobre as competências e as habilidades de cada componente curricular na prática em sala de aula. Embora o texto da BNCC ostente teorias e metodologias modernas de ensino e aprendizagem, como os multiletramentos, ele não deixa claro quem são os sujeitos responsáveis pelas ações e pelas atividades performadas em sala de aula, da mesma forma que também não demonstra como operacionalizar tais abordagens em sala de aula. Nesse sentido, podemos perceber um distanciamento entre teoria e prática, isto é, o documento aborda teorias e metodologias contemporâneas de linguagem, porém não explicita de que maneira essas teorias e metodologias podem ser concretizadas no ambiente escolar e, tampouco, quem seria responsável por desenvolver tais práticas no contexto escolar. Assim, sendo a BNCC um documento político normativo do ensino no Brasil, há um esvaziamento de responsabilidade. Em outras palavras, podemos nos perguntar: quem seria o responsável efetivo por essa mudança na prática do professor de linguagens em sala de aula? E ainda, se o texto da base enfatiza um ensino de línguas multiletrado, como isso seria operacionalizado e concretizado nas escolas públicas brasileiras, visto que muitas não oferecem subsídios tecnológicos mínimos? Nesse paradigma, muitos questionamentos ainda permanecem em relação à implementação da $\mathrm{BNCC}$ e, portanto, mais investigações precisam ser conduzidas sobre o assunto.

Por fim, acreditamos ser necessário um estudo minucioso sobre as representações de letramento na BNCC que se expanda para as outras áreas do conhecimento a fim de analisar e comparar se as representações encontradas são recorrentes ou não em relação às representações encontradas neste artigo. 


\section{Referências}

ALVES, M. R. B. A representação da educação em O Estado de S. Paulo e na Folha de S. Paulo: um enfoque sistêmico-funcional. 2016. 98f. (Dissertação) - Mestrado em Linguística Aplicada e Estudos da Linguagem, Pontifícia Universidade Católica de São Paulo, São Paulo, 2016.

BARTON, D.; HAMILTON, M. Local literacies: reading and writing in one community. London/New York: Routledge, 2012.

BATISTA, M. E. Implicações socioeducacionais do ensino de inglês em escolas públicas: linguística sistêmico-funcional e representação da prática pedagógica. 2012. 286f. (Tese) - Doutorado em Linguística Aplicada e Estudos da Linguagem), Pontifícia Universidade Católica de São Paulo, São Paulo, 2012.

BRASIL. Constituição. Constituição da República Federativa do Brasil. Brasília: Senado Federal: Centro Gráfico, 292p, 1988.

. Ministério de Educação e Cultura. LDB - Lei n. 9.394/1996, de 20 de dezembro de 1996. Estabelece as diretrizes e bases da Educação Nacional. Brasília: Ministério da Educação, MEC, 1996. Disponível em: $<$ http://www.planalto.gov.br/ccivil_03/leis/L9394.htm>. Acesso em: 25 jan. 2018.

Secretaria de Educação Básica. Orientações curriculares para o ensino médio: linguagens, códigos e suas tecnologias. Brasília: Ministério da Educação, Secretaria de Educação Básica, 2006. Disponível em: <http://cenp.edunet.sp. gov.br/Ens_medio/em_pcn.htm>. Acesso em: 14 mar. 2018.

. Ministério de Educação e Cultura. Lei n. 13.005, de 25 de junho de 2014. Aprova o Plano Nacional de Educação - PNE e dá outras providências. Brasília: Ministério da Educação, MEC, 2014. Disponível em: < http://www.planalto.gov.br/CCIVIL_03/_Ato20112014/2014/Lei/L13005.htm >. Acesso em: 01 mai. 2018. 
Representações de letramento na BNCC...

- Secretaria de Educação Básica. Base Nacional Comum Curricular: educação é a base. Ministério da Educação. Brasília: MEC, 2017.

Disponível

em:

<http://basenacionalcomum.mec.gov.br/\#/site/inicio>. Acesso em: 20 jan. de 2018.

CARGNIN, E. C.; FUZER, C. Representações de professor em discursos de paraninfos da área de letras. In.: FUZER, C.; SILVA, T. S. (Org.). Linguagem e representações: estudos em linguística sistêmicofuncional. Santa Maria: PPGL Ed., 19-48, 2017.

COPE, B.; KALANTZIS, M. Multiliteracies: new ILiteracies, new learning. pedagogies: An International Journal, v. 4, n. 3, p. 164-195, 2009.

CORAZZA, S. M. Base Nacional Comum Curricular: apontamentos crítico-clínicos e um trampolim. Educação PUCRS, v. 39, p. s135-s144, 2016. doi: 10.15448/1981-2582.2016.s.23591.

CORRÊA, A.; MORGADO, J. C. A construção da Base Nacional Comum Curricular no Brasil: tensões e desafios. Colóquio LusoBrasileiro de Educação-COLBEDUCA, v. 3, p. 1-12, 2018.

DEVRIM, D. Y. Grammatical metaphor: What do we mean? What exactly are we researching? Functional Linguistics, v. 2, n. 3, p. 1-15, 2015. doi: 〈https://doi.org/10.1186/s40554-015-0016-7>.

FREIRE, P. A importância do ato de ler: em três artigos que se completam, v. 22, 51. ed. São Paulo: Cortez, 2011.

FUZER, C.; CABRAL, S. S. Introdução à gramática sistêmicofuncional. Campinas: Mercado de Letras, 2014.

FUZER, C.; CABRAL S. R. S.; OLIONI, R. C. A seleção brasileira de futebol

serviço da cerveja: análise multifuncional de texto na perspectiva da gramática sistêmico-funcional. Calidoscópio, v. 9, n. 3), 2011. 
GOUVEIA, C. Texto e gramática: uma introdução à linguística sistêmico-funcional. Matraga, Rio de Janeiro, v. 16, n. 24, p. 13-47, doi: 10.12957/matraga, 2009.

HALLIDAY, M. A. K.; MATTHIESSEN, C. M. I. M. An introduction to functional grammar. 3 ed., London: Arnold, 2004.

Halliday's introduction to functional grammar. 4 ed., Abingdon: Routledge, 2014.

LIMA-LOPES, R. E.; VENTURA, C. S. M. A transitividade em Português. Direct Papers, v. 55, São Paulo, PUC-SP, 2008.

MEC. Base Nacional Comum Curricular: BNCC. Portal do Ministério da Educação, 2017. Disponível em: <http://portal.mec.gov.br/conselhonacional-de-educacao/base-nacional-comum-curricular-bncc $>$. Acesso em: 22 set. 2018.

MARTIN, J. R. Life as a noun: arresting the universe in Science and Humanities. Writing Science, p. 221-267, 1996.

MONTE MOR, W. Learning by design: reconstructing knowledge processes in teaching and learning practices. In.: COPE, B.; KALANTZIs, M. (Org.). A pedagogy of multiliteracies: learning by design. Palgrave Macmillan, p. 186-209, 2015.

OLIVEIRA, M. S. Gêneros textuais e letramento. Revista Brasileira de Linguística Aplicada, v. 10, n. 2, p. 325-345. doi: <http://dx.doi.org/10.1590/S1984-63982010000200003>, 2010.

RIO GRANDE DO SUL. Secretaria Estadual de Educação. Caderno lições do Rio Grande: linguagens, códigos e suas tecnologias. Porto Alegre: SE/DP, 2009.

ROJO, R. Letramento e capacidades de leitura para a cidadania. São Paulo, SEE: CENP, 2004. 
Representações de letramento na BNCC...

. Letramentos múltiplos: escola e inclusão social. São Paulo: Parábola Editorial, 2009.

ROJO, R.; MOURA, E. (Org.) Multiletramentos na escola. São Paulo: Parábola Editorial, 2012.

SOARES, M. Novas práticas de leitura e escrita: letramento na cibercultura. Educ. Soc. Campinas, v. 23, n. 81, p. 143-160. doi: $<$ http://dx.doi.org/10.1590/S0101-73302002008100008>, 2002.

SOARES, M. B.; BATISTA, A. A. G. Alfabetização e letramento: caderno do professor. (Coleção Alfabetização e Letramento). Belo Horizonte: Ceale/FaE/UFMG, 2005.

SUSSEKIND, M. L. As (im)possibilidades de uma Base Comum Nacional. Revista e-Curriculum, São Paulo, v. 12, n. 3, p.1512-1529 out./dez. 2014.

THE NEW LONDON GROUP. A pedagogy of multiliteracies: designing social futures. In: COPE, B.; KALANTZIS, $\mathrm{M}$. Multiliteracies: literacy learning and the design of social futures. London: Routledge, 1996-2000. p. 9-37.

VAN LEEUWEN, T. A representação dos actores sociais. In: PEDRO, E. R. (Org.). Análise crítica do discurso. Lisboa: Caminho, 1997.

Recebido em: 09/03/2019

Aceito em: 02/10/2019

Title: Representations of literacy in the Elementary Education National Common Curricular Base for Portuguese and English 